\title{
Mismatch repair deficiency is associated with specific morphologic features and frequent loss of ARID1A expression in ovarian clear cell carcinoma
}

Huijuan Ge $\mathrm{e}^{1,3}$, Yaoxin Xiao ${ }^{2,3}$, Guangqi Qin ${ }^{1,3}$, Yanzi Gu ${ }^{1,3}$, Xu Cai $^{1,3}$, Wenhua Jiang ${ }^{1,3}$, Xiaoyu Tu ${ }^{1,3}$, Wentao Yang ${ }^{1,3}$ and Rui $\mathrm{Bi}^{1,3^{*}}$

\begin{abstract}
Background: Ovarian clear cell carcinoma (OCCC) is the second subtype of ovarian epithelial carcinoma reported to be closely related to Lynch syndrome (LS). ARID1A mutation is an important pathogenetic mechanism in OCCC that leads to loss of ARID1A expression in approximately half of OCCCs. However, the correlation of MMR status and ARID1A deficiency is unclear. The current study aimed to identify the clinical and histopathological characteristics of OCCC associated with $\mathrm{AMMR}$ and to further explore the association between dMMR and ARID1A deficiency.

Methods: A cohort of 176 primary OCCC patients was enrolled and review included histological characteristics (nuclear atypia, necrosis, mitosis, stromal hyalinization, and background precursors) and host inflammatory response (tumor-infiltrating lymphocytes, peritumoral lymphocytes, intratumoral stromal inflammation and plasma cell infiltration). Immunohistochemical staining of MLH1, PMS2, MSH2, MSH6 and ARID1A was performed using tissue microarrays.

Results: dMMR was detected in 10/176 tumors (6\%), followed by MSH2/MSH6 (6/176), MLH1/PMS2 (3/176), and MSH6 (1/ 176). The average age of patients with dMMR was younger than that of patients with intact MMR (46 y vs. $53 \mathrm{y})$. Tumors with diffuse intratumoral stromal inflammation remained significantly associated after multivariate analysis. ARID1A expression was absent in 8 patients with dMMR (8/10), which is a significantly higher frequency than that observed in patients with intact MMR ( $80 \%$ vs. $43.2 \%)$.

Conclusions: Our study indicates that diffuse intratumoral stromal inflammation of OCCCs is associated with dMMR, with loss of MSH2/MSH6 expression being most frequent. dMMR is strongly associated with the loss of ARID1A expression in OCCC.
\end{abstract}

Keywords: Ovarian clear cell carcinoma, Deficient MMR (dMMR), Diffuse intratumoral stromal inflammation, MSH2/MSH6, ARID1A

\footnotetext{
* Correspondence: br_fdcc@163.com

'Department of Pathology, Fudan University Shanghai Cancer Center, Fudan University, 270 Dong An Road, 200032 Shanghai, China

${ }^{3}$ Department of Oncology, Shanghai Medical College, Fudan University, Shanghai, China

Full list of author information is available at the end of the article
}

(c) The Author(s). 2021 Open Access This article is licensed under a Creative Commons Attribution 4.0 International License, which permits use, sharing, adaptation, distribution and reproduction in any medium or format, as long as you give appropriate credit to the original author(s) and the source, provide a link to the Creative Commons licence, and indicate if changes were made. The images or other third party material in this article are included in the article's Creative Commons licence, unless indicated otherwise in a credit line to the material. If material is not included in the article's Creative Commons licence and your intended use is not permitted by statutory regulation or exceeds the permitted use, you will need to obtain permission directly from the copyright holder. To view a copy of this licence, visit http://creativecommons.org/licenses/by/4.0/ The Creative Commons Public Domain Dedication waiver (http://creativecommons.org/publicdomain/zero/1.0/) applies to the data made available in this article, unless otherwise stated in a credit line to the data. 


\section{Introduction}

Lynch syndrome (LS) is an autosomal dominant predisposition toward neoplasia caused predominantly by germline mutations in one of four DNA mismatch repair (MMR) genes, including MLH1, MSH2, MSH6 and PMS2 [1], and rarely by EpCAM (epithelial cell adhesion molecule) deletions, which cause MSH2 promoter methylation and ultimately inactivation [2]. A loss-offunction mutation in the normal allele increases cancer risk [3] and is the most common cause of colon cancer and familial endometrial carcinoma. It has also been associated with an increased risk of other cancers, such as renal pelvis/ ureter, stomach, small bowel, and brain cancer [4].

Among gynecologic cancers, endometrial carcinoma is the most common tumor related to LS, followed by ovarian cancer, with cumulative lifetime risks of 21$71 \%[5,6]$ and $6-12 \%[7,8]$, respectively. Although endometrial carcinoma surveillance can be effective, the value of ovarian cancer surveillance is still controversial. Ovarian cancer with LS is frequently of the endometrioid/clear cell carcinoma histological type [3, 9, 10]. Ovarian clear cell carcinoma (OCCC) is the second reported subtype of ovarian epithelial carcinoma that is closely related to LS, with a mean age at diagnosis of 55 years, and is strongly associated with endometriosis and adenofibromatous components [11]. Several reports have demonstrated that tumor-infiltrating lymphocytes (TILs) and peritumoral lymphocytes in endometrioid carcinoma indicate deficient MMR (dMMR) [12-14]. However, morphological features indicating $\mathrm{dMMR}$ in OCCCs have rarely been described. Although Bennett et al. reported diffuse intratumoral stromal inflammation to be an indicator of dMMR in OCCCs [15], no further research has been performed to confirm this finding.

The ARID1A gene encodes the BAF250A protein, and abnormalities in this gene or loss of protein expression have been shown to be key and early molecular events in the progression of OCCC $[16,17]$; additionally, PIK3CA or PTEN alterations appear to be required for this process $[18,19]$. Inactivation of the ARID1A subunit is observed in approximately half of all OCCCs [16, 20], although no reports have examined the relationship between ARID1A and MMR expression in OCCCs.

In this study, we aimed to identify the clinical and histopathological characteristics of OCCC associated with $\mathrm{dMMR}$ and to further examine the relationship between $\mathrm{dMMR}$ and ARID1A expression.

\section{Materials and Methods}

\section{Patients and tissue samples}

A cohort of 176 unselected primary OCCC patients was enrolled at the Department of Pathology, Fudan University Shanghai Cancer Center from 1999 to 2016. Tumor specimens were collected after obtaining written consent from all patients with the approval of the Facility Ethical Committee (Fudan University Cancer Center Ethics Committee, China; approval No. 050432-4-121B, 13 December 2012).

All cases were reviewed, and the diagnosis was confirmed by two pathologists ( $\mathrm{Dr}$ Ge and Dr Bi). All 176 cases were pure OCCCs, including two cases of synchronous endometrial endometrioid carcinoma. The following clinical data were extracted from the medical history and examination records: age, tumor size, and Federation of Gynecology and Obstetrics (FIGO) stage. All international FIGO stages were reclassified according to the 2014 FIGO guidelines [21].

\section{Tissue microarray (TMA) construction}

Hematoxylin-eosin (HE)-stained slides were reviewed by $\mathrm{Dr} \mathrm{Ge}$ and $\mathrm{Dr} \mathrm{Bi}$, and an abundant tumor cell area was chosen for TMA construction.

The TMA was prepared using triplicate core samples from 176 OCCCs to achieve a high level of standardization for immunohistochemical analysis [22]. Triplicate 1-mm tissue cores were taken from each targeted donor block, and a receptor block was inserted. Four-micrometer sections were cut and stained with H\&E to confirm the histologic diagnosis. Unstained slides were used for immunohistochemical staining.

\section{Immunohistochemistry}

Immunohistochemical staining was performed on TMAs with the Ventana Benchmark XT platform. The following panel of antibodies was used: anti-MLH1 (clone G168728, Roche), -PMS2 (clone EPR3947, Roche), -MSH2 (clone G219-1129, Roche), -MSH6 (clone 44, Roche), and -ARID1A (clone D2A8U, Roche). According to the published criteria of abnormal expression of MMR and ARID1A [15, 23], both markers were interpreted as loss of expression, whereas no tumor cells were stained.

We chose the recommended guidelines that the immunohistochemistry results be reported in a binary manner, either positive (indicating intact mismatch repair, showing intact nuclear expression in tumor cells) or negative (indicating deficient mismatch repair, showing nuclear expression completely lost in tumor cells) $[24,25]$ Nuclei of lymphocytes and ovarian stromal cells served as positive internal controls. All staining results were reviewed by the above 2 pathologists. Because immunohistochemical examination was performed using a tissue microarray, when deficient mismatch repair (dMMR) was observed, the immunohistochemistry procedure was repeated on whole-slide sections to avoid heterogeneous expression, such as for MSH6 [26]. Ultimately, MMR protein restaining was performed in 51 instances involving 27 of 176 cases; ARID1A restaining was performed in 15 instances involving 3 cases of dMMR among 135 cases. 


\section{Morphologic assessment}

All tumor slides were evaluated by $\mathrm{Dr} \mathrm{Ge}$ and $\mathrm{Dr} \mathrm{Bi}$, who were blinded to the MMR status, and an average of 7 tumor slides per case (range 1-17) were examined. The following features were assessed (in brief) [8].

\section{Host inflammatory response}

(1) TILs - defined only as lymphocytes located within the boundary of tumor cells or glands were counted, especially in regions of high tumor density and minimal stroma. Areas showing the greatest number of lymphocytes at low-power magnification were randomly selected, and the numbers of lymphocytes were counted in 10 high-power microscopic fields (HPFs). Apoptotic bodies and stromal lymphocytes were not counted (Fig. 1a).

(2) Intratumoral stromal inflammation - defined as inflammation in the stroma between tumor cells, nests, or glands that is evident at low-power magnification - was graded as diffuse (marked inflammatory infiltrate present in multiple foci or on multiple slides), focal (partially present in the stroma with inflammation) or absent (8). (Fig. 1b). Areas of necrosis and infarction were excluded.
(3) Peritumoral lymphocytes - defined as peritumoral lymphocytes present at low-power magnification were categorized as present or absent (Fig. 1c).

(4) Plasma cell infiltration - defined as the percentage of plasma cells in the intratumoral stroma - was classified as $<10 \%, 10-50 \%$, or $>50 \%$ (Fig. 1d).

\section{Tumor characteristics}

(1) Background precursor - evaluated based mainly on the benign element adjacent to the tumor in the same section, categorized as a tumor arising as endometriosis, adenofibroma, both, or neither.

(2) Architectural pattern - included tubulocystic, papillary, glandular, solid or mixed.

(3) Stromal hyalinization - graded as diffuse, focal, or absent.

(4) Nuclear atypia - high cytologic grade demonstrating variations of greater than 3 times the nuclear size, highly irregular nuclear contours, striking hyperchromasia, and/or prominent nucleoli. Areas constituting at least $10 \%$ of the tumor were considered high grade; other areas were considered low grade.

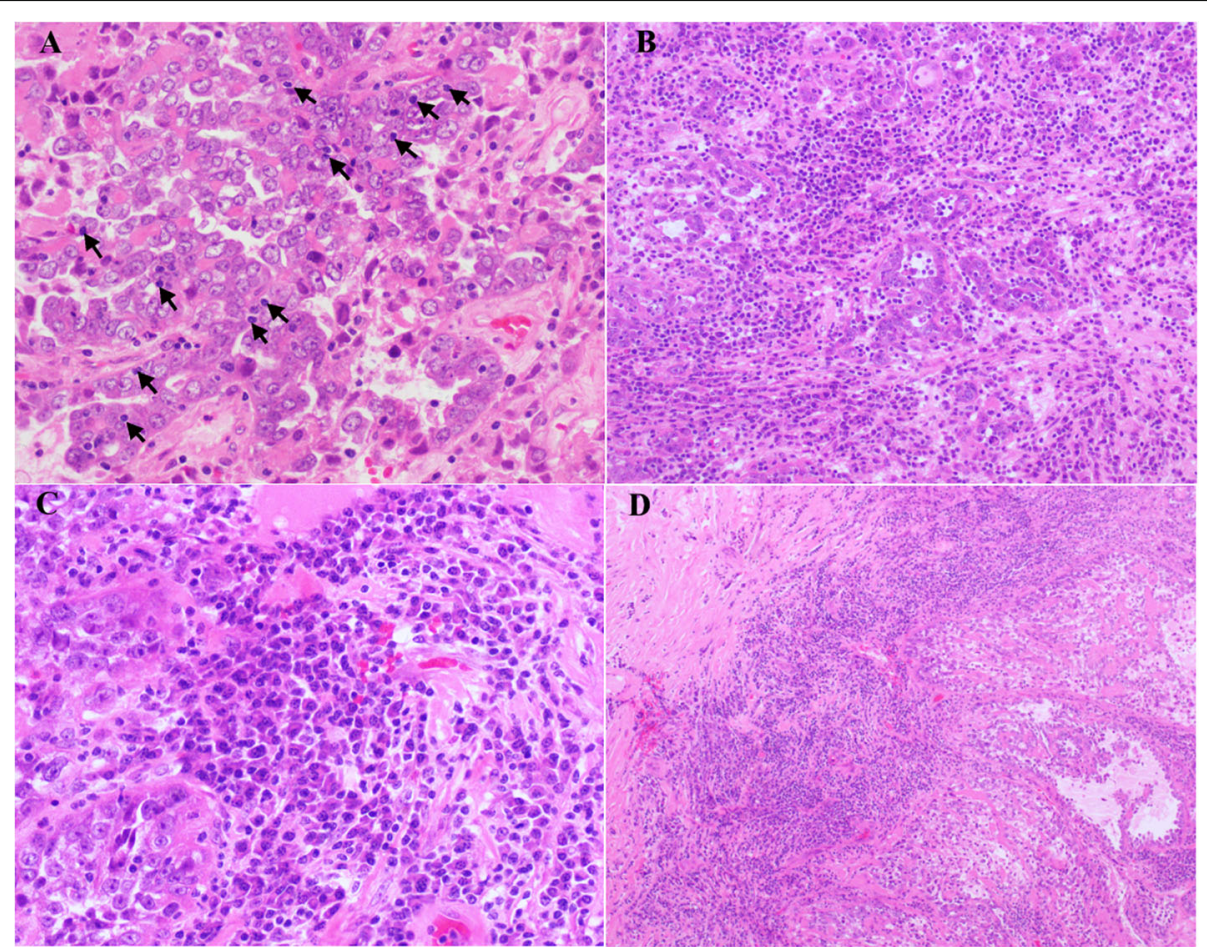

Fig. 1 Tumor-infiltrating lymphocytes (TILs) (a, arrows) in tumor cells, diffuse intratumoral stromal inflammation (b), composed mostly of plasma cells (c), and peritumoral lymphocytes (d) were observed 
(5) Specific morphology (signet ring cells) - defined as present or absent.

(6) Tumor necrosis - defined as present when there were geographic foci of tumor cell necrosis. Areas of necrosis only within glands or at the tumor's surface were not included.

\section{Follow-up}

Overall survival (OS) was defined as the time from the operation to either death or the last follow-up. Diseasefree survival (DFS) was defined as the interval from the operation to disease recurrence or the last follow-up. We defined disease recurrence as a consistent elevation in CA125 or detection of a tumor by a clinical examination, including a physical examination and imaging [27]. The patients were followed up until December 2018 by medical records or telephone.

\section{Statistical analysis}

Statistical analysis was conducted using SPSS version 20.0 software (IBM, SPSS Statistics Armonk, NY, and USA). Univariate analysis of categorical variables was performed with the chi-square test and Fisher's exact test; multivariate analysis was performed with exact logistic regression to identify independent predictors of abnormal MMR expression. Survival analysis was performed using the Kaplan-Meier univariate method. Differences in survival curves were determined with logrank tests. $P$ values $<0.05$ were considered statistically significant.

\section{Results}

\section{Clinicopathological factors}

Patients with $\mathrm{dMMR}$ were younger than those with intact MMR (ranging from 28 to $45 \mathrm{y}$, mean $46 \mathrm{y}$ vs. range 22-83 y, mean 53 y, $P=0.041$ ). Macroscopically, the tumor size ranged from 6 to $20 \mathrm{~cm}$ (mean $11.25 \pm$ $5.5 \mathrm{~cm}$ ). Tumors occurred on the right side of the ovary in 80 patients $(45.4 \%)$ and on the left side of the ovary in $64(36.4 \%)$; 32 patients (18.2\%) had bilateral tumors. More than half of the cases were stage I/II (66\%, 116 patients), whereas 60 cases were stage III/IV (34\%). In the dMMR group, 2 patients had synchronous malignant tumors (uterus endometrioid carcinoma, grade I-II), and 2 patients had a history of hereditary nonpolyposis colorectal cancer (HNPCC).

\section{Histological characteristics}

Among the morphologic variables evaluated, intratumoral stromal inflammation and plasma cell infiltration were both significantly associated with MMR status. Patients with $\mathrm{dMMR}$ and intact MMR exhibited no significant differences in endometriosis, adenofibromatous background, TILs, peritumoral lymphocytes, necrosis, stromal hyalinization, grade or stage (Table 1).

\section{Host inflammatory response}

Prominent intratumoral stromal inflammation and > $50 \%$ plasma cells were both more frequent in tumors with dMMR ( $P=0.001$ and $P=0.037$, respectively), but only diffuse intratumoral stromal inflammation correlated significantly with $\mathrm{dMMR}$ in multivariate analysis $(P=0.004$, Table 2$)$.

\section{Relationship between dMMR and ARID1A expression}

A total of 176 patients underwent immunohistochemical analysis for MMR, among which only 10/176 (6\%) exhibited dMMR after restaining on the whole slides. The most frequently absent MMR protein was MSH2/MSH6, in 6/10 (60\%) dMMR patients (Fig. 2), followed by MLH1/PMS2 in $3 / 10$ patients (30\%); 1 patient (1/10, $10 \%)$ showed isolated loss of MSH6. In total, ARID1A staining was successful for 135 cases, including 62 with loss of expression (46\%) and 73 with intact expression. Among the 10 dMMR patients, 2 exhibited ARID1A staining, but $8(80 \%)$ were deficient (Table 3$)$; for patients with intact MMR, 54 (43\%) exhibited loss of ARID1A, and 71 (57\%) showed positive expression. There was a significant frequent loss of ARID1A expression in AMMR OCCC compared to intact MMR OCCC ( $80 \%$ vs. $43 \%, P=0.027$, Fig. 3 ).

\section{Follow-up}

Follow-up information was available for $97.2 \%$ (171/ 176) of patients, and the mean and median follow-up times were 57 and 46.7 months, respectively (range, 0.9187.7 months). The OS and 5-year OS rates were 119/ $171(67.7 \%)$ and 26/171 (71.6\%), respectively. No significant differences in OS or DFS $(P=0.920$ and $P=$ 0.974 , respectively) between the $\mathrm{dMMR}$ and intact MMR patients were found.

\section{Discussion}

The rate of MMR deficiency has been reported to be 12 $13.8 \%$ in a large cohort of ovarian endometrioid carcinoma patients $[10,28] 2$ and $2 \%-6 \%$ in OCCC patients [10, 15, 29, 30] In our cohort, ten patients with dMMR were observed among 176 OCCC patients $(10 / 176,6 \%)$, which is a similar frequency to that reported by Bennett et al. for 109 OCCC patients $(6 / 109,6 \%)$ [15] but higher than the rate of $2.4 \%$ reported by Rambau et al [10]. Based on data from these two previous studies $[10,15]$ and our series, the dMMR frequency in ovarian cancer differs from that in endometrial carcinoma. The highly frequent deficiency of MSH2/MSH6 or MSH6 expression in ovarian endometrioid carcinoma and 
Table 1 Pathologic characteristics of clear cell carcinoma and their association with MMR status

\begin{tabular}{|c|c|c|c|}
\hline & MMR-deficient cases $(n=10)$ & MMR-intact cases $(n=166)$ & $\mathbf{P}$ \\
\hline $\operatorname{Age}(y)$ & & & 0.078 \\
\hline$<50$ & $6(60 \%)$ & $54(32.5 \%)$ & \\
\hline$\geq 50$ & $4(40 \%)$ & $112(67.5 \%)$ & \\
\hline Median & & 53 & 0.041 \\
\hline Family history of cancer & 2 & 39 & 1.0 \\
\hline HNPCC history & 2 & 20 & 0.362 \\
\hline $\begin{array}{l}\text { Precursor } \\
\text { Not present } \\
\text { Adenofibroma } \\
\text { Endometriosis } \\
\text { both }\end{array}$ & $\begin{array}{l}4(40 \%) \\
1(10 \%) \\
4(40 \%) \\
1(10 \%)\end{array}$ & $\begin{array}{l}61(36.7 \%) \\
22(13.3 \%) \\
69(41.6 \%) \\
14(8.4 \%)\end{array}$ & 0.987 \\
\hline Stromal Hyalinization & & & 0.671 \\
\hline Focal or absent & $8(80 \%)$ & $139(83.7 \%)$ & \\
\hline Diffuse & $2(20 \%)$ & $27(16.3 \%)$ & \\
\hline Nuclear Atypia & & & 0.139 \\
\hline High grade & $5(50 \%)$ & $43(25.9 \%)$ & \\
\hline Low-medium grade & $5(50 \%)$ & $123(74.1 \%)$ & \\
\hline Signet ring cells & & & 0.603 \\
\hline Not present & $10(100 \%)$ & $147(88.6 \%)$ & \\
\hline Present & $0(0 \%)$ & $19(11.4 \%)$ & \\
\hline Peritumoral Lymphocytes & & & 0.127 \\
\hline Not present & $7(70 \%)$ & $146(88 \%)$ & \\
\hline Present & $3(30 \%)$ & $20(12 \%)$ & \\
\hline Intratumoral Stromal Inflammation & & & 0.001 \\
\hline Diffuse & $5(50 \%)$ & $11(6.6 \%)$ & \\
\hline Focal & $5(50 \%)$ & $155(93.4 \%)$ & \\
\hline Plasma Cell Component & & & 0.037 \\
\hline$\leq 50 \%$ & $6(60 \%)$ & $145(87.3 \%)$ & \\
\hline$>50 \%$ & $4(40 \%)$ & $21(12.7 \%)$ & \\
\hline Tumor infiltrating Lymphocytes (/10HPF) & & & 0.249 \\
\hline$<40$ & $8(80 \%)$ & $151(91 \%)$ & \\
\hline$\geq 40$ & $2(20 \%)$ & $15(9 \%)$ & \\
\hline Mitosis (/10HPF) & 5.1 & 6.4 & 0.499 \\
\hline Necrosis & & & 0.300 \\
\hline Not present & $3(30 \%)$ & $73(44 \%)$ & \\
\hline Present & $7(70 \%)$ & $93(56 \%)$ & \\
\hline ARID1A (135 cases) & & & 0.027 \\
\hline Negative & $8(80 \%)$ & $54(43.2 \%)$ & \\
\hline Positive & $2(20 \%)$ & $71(56.8 \%)$ & \\
\hline Stage & & & 0.462 \\
\hline$|/| \mid$ & 6 & 110 & \\
\hline III-IV & 4 & 56 & \\
\hline
\end{tabular}


Table 2 Multinomial logistic regression for morphologic features indicating dMMR in OCCCs

\begin{tabular}{lcc}
\hline & Relative risk $(\mathbf{9 5} \% \mathrm{Cl})$ & $\boldsymbol{P}$ value \\
\hline Intratumoral Stromal Inflammation & \\
Diffuse vs. focal & $0.048(0.006-0.409)$ & 0.004 \\
Plasma Cell Component & & \\
$\leq 50 \%$ vs. $>50 \%$ & $1.702(0.187-15.522)$ & 0.632 \\
\hline
\end{tabular}

OCCC, as opposed to the most MHL1/PMS2 expression deficiency in endometrial carcinoma [14, 31], indicates a high probability of LS. Further, further studies are needed to examine MMR germline mutations and MLH1 promoter hypermethylation in our cohort.

The average age of patients with dMMR was $46 \mathrm{y}$ in our series, with an age range of $28-58 \mathrm{y}$, which was younger than that of individuals with intact MMR (mean $53 \mathrm{y}$, range of 22-83 y), and $60 \%$ of patients were younger than $50 \mathrm{y}$. dMMR was observed in $10 \%$ of all patients under 50 y $(6 / 60,10 \%)$, which was a higher frequency than that observed in the whole series $(6 \%)$. However, the prevalence among our cohort was less than the rate of $17 \%$ reported by Jensen et al [32]. This is comparable with the age at diagnosis in 747 ovarian cancer patients with LS described in a recent review of the literature, with a mean age of 45.3 y (range 19-92 y)
[33], and with a recently published cohort study of 53 ovarian cancers in LS with a mean age of $51 \mathrm{y}$ (range 24-70 y) [34]. LS-associated ovarian cancer seems to occur approximately 15-20 y earlier than sporadic ovarian cancer [35]. Interestingly, OCCC synchronous with grade I-II endometrial endometrioid carcinoma, which is probably sporadic but does not completely exclude LS, was noted in 2 of $3 \mathrm{MLH} 1 / \mathrm{PMS} 2$-deficient patients. In addition, synchronous tumors in the ovary and endometrium have been hypothesized to likely be sporadic [36]. However, Martin et al [37] investigated the frequency of MMR protein deficiency in a large series of endometrial mixed endometrioid and clear cell carcinomas detecting it in $27(27 / 41,66 \%)$ cases. Of these 27 MMR-deficient tumors, most $(16,59 \%)$ showed concurrent MLH1 and PMS2 loss. These results are consistent with our findings. The pattern of MMR protein deficiency was identical between the corresponding endometrioid and clear cell components in all MMR proteindeficient cases.

Although several morphologic features are believed to be associated with abnormal MMR in endometrial and colonic carcinomas $[12,14]$, TILs, as a predictive morphologic feature, are not associated with OCCC or ovarian endometrioid carcinoma [9, 28]. Bennett et al. first presented diffuse intratumoral stromal inflammation and
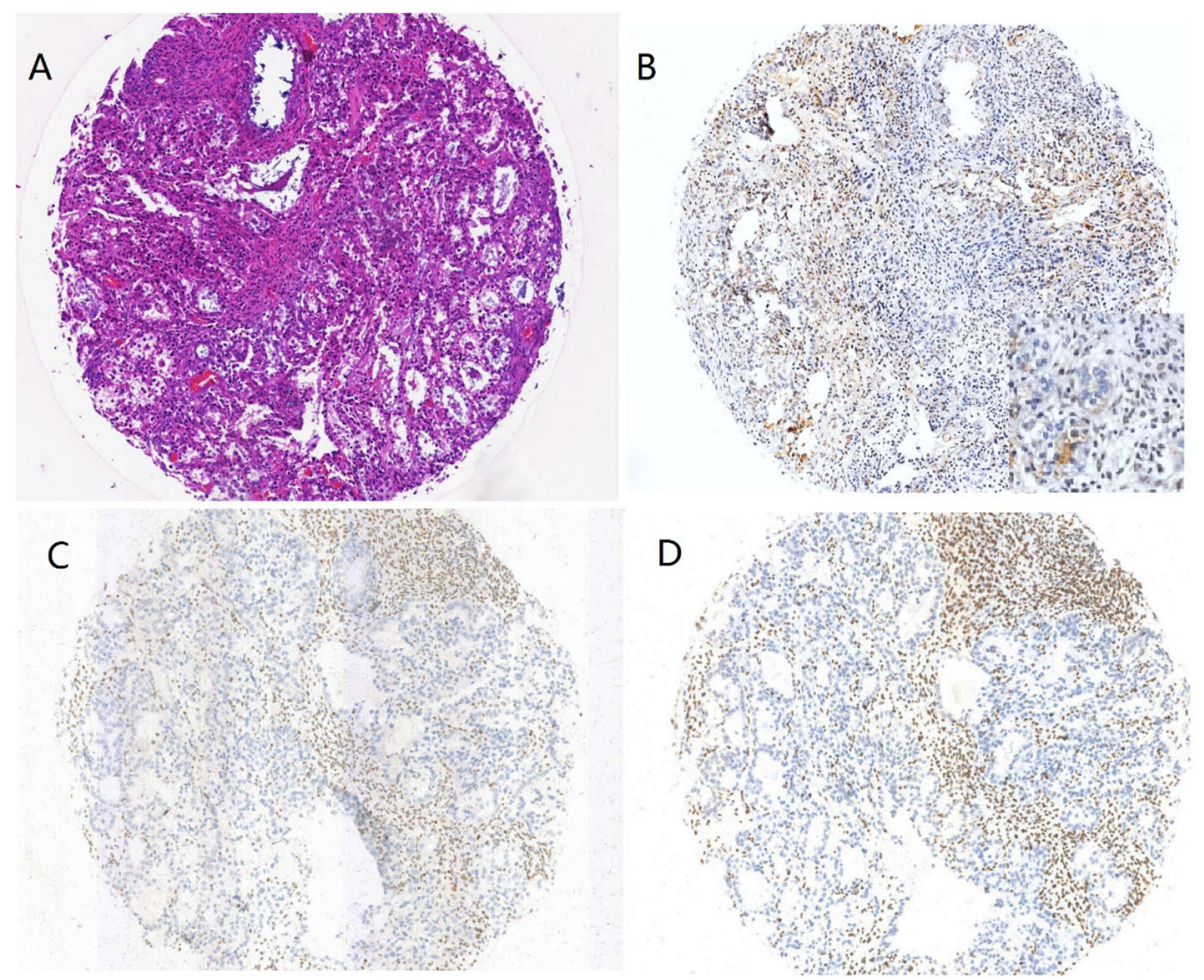

Fig. 2 One case (CCC_085) (HE, a) showed a synchronous loss of ARID1A (b), MSH2 (c) and MSH6 (d) expression 
Table 3 MMR deficient cases with expression of ARID1A

\begin{tabular}{lllll}
\hline MLH1 & PMS2 & MSH2 & MSH6 & ARID1A \\
\hline 0 & 0 & 1 & 1 & 0 \\
0 & 0 & 1 & 1 & 0 \\
0 & 0 & 1 & 1 & 0 \\
1 & 1 & 1 & 0 & 0 \\
1 & 1 & 0 & 0 & 0 \\
1 & 1 & 0 & 0 & 1 \\
1 & 1 & 0 & 0 & 1 \\
1 & 1 & 0 & 0 & 0 \\
1 & 1 & 0 & 0 & 0 \\
1 & 1 & 0 & 0 & 0 \\
\hline
\end{tabular}

0: MMR deficient; 1: MMR intact

peritumoral lymphocytes as 2 potential features predictive of $\mathrm{dMMR}$ in OCCC [15]. In our cohort, we further confirmed that diffuse intratumoral stromal inflammation is an independent feature associated with dMMR status, offering the possibility of economical screening because of the low frequency of dMMR (usually $<10 \%$ ) in OCCC.

In one series [38], The lack of an adenofibromatous background was found to be predictive of dMMR in ovarian endometrioid carcinoma, although none of our dMMR OCCC patients showed such a background. Tumor grade, stage, size, endometriosis, and mitotic index were also unrelated to MMR status.

Loss of ARID1A is a frequent event in OCCC, with 35-61 \% of patients exhibiting deficiency in ARID1A expression [16, 39-41] We detected loss of ARID1A expression in $46 \%$ of OCCCs, and $6 \%$ of these cases indicated dMMR. It is worth noting that the dMMR patients exhibited a high frequency of loss of ARID1A expression in our cohort $(\mathrm{P}=0.027)$. This is consistent with reports of colorectal carcinoma [42], gastric carcinoma [43], endometrial carcinoma [44, 45] and ovarian endometrioid carcinoma [10], indicating a correlation between $\mathrm{dMMR}$ and loss of ARID1A expression. ARID1A mutation is the core mechanism of OCCC and exhibits a correlation with loss of the protein $[16,17]$. Moreover, loss of ARID1A is significantly associated with microsatellite instability (MSI), predominantly resulting from sporadic MSI (MLH1 promoter hypermethylation), in endometrial cancer [44]. ARID1A deficiency impairs the DNA damage checkpoint [46], which is targeted by the MSI mechanism of DNA damage in gastric cancer [43], and ARID1A recruits MSH2 to chromatin during DNA replication and promotes MMR [47]. Taken together, these findings may contribute to the association of the loss of ARID1A expression with dMMR.

Although we did not find statistically significant differences in OS and DFS between dMMR and intact MMR patients, the results indicated that the mean survival period was longer in patients with dMMR than in patients with intact MMR (140 months vs. 116 months for OS; 120 months vs. 100 months for DFS). Two factors likely contribute to the lack of difference between the dMMR and intact MMR groups: one is that all-cause survival data rather than disease-specific survival data were investigated, and the other factor may be related to the high percentage of dMMR patients who were lost to follow-up (20\%). Stewart et al. reported two patients

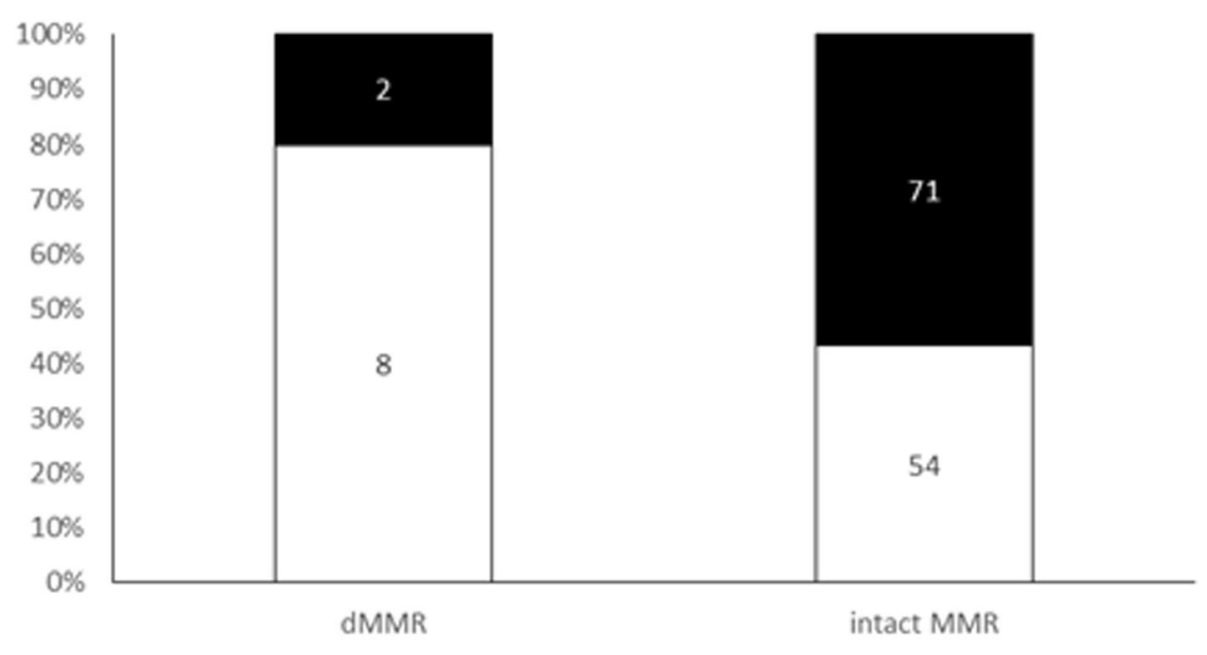

Dloss of ARID1A

ARID1A expression

Fig. 3 Distribution of ARID1A expression in OCCC. Loss of ARID1A expression was more frequent in dMMR OCCC than in intact MMR OCCC (80\% vs. $43 \%, P=0.027)$ 
who showed loss of MSH2/MSH6 expression and were alive at 160 months and 124 months with stage III/IV OCCCs [48].

\section{Conclusions}

To our knowledge, the current study is the largest series to explore the MMR expression status and the clinicopathologic features of consecutive OCCC cases. We conclude that dMMR occurs in a small proportion of patients but indicates intratumoral stromal inflammation in OCCCs, which correlates with loss of ARID1A expression. Loss of MSH2/MSH6 expression is the most common deficiency pattern.

\section{Abbreviations \\ OCCC: Ovarian clear cell carcinoma; LS: Lynch syndrome; MMR: Mismatch repair; dMMR: Deficient MMR; TILs: Tumor-infiltrating lymphocytes; TMA: Tissue microarray; HE: Hematoxylin-eosin; HPFs: High-power microscopic fields; OS: Overall survival; DFS: Disease-free survival; HNPC C: Hereditary nonpolyposis colorectal cancer}

\section{Acknowledgements}

We gratefully acknowledge technical assistance from members of the Department of Pathology, shanghai cancer center.

\section{Authors' contributions}

We thank all patients, investigators, and coordinators who participated in the study. H.G. and R.B. carried out the pathological diagnosis and drafted the manuscript. Y.X contributed to the data collection. G.Q and Y.G. constructed the tissue microarray. X.C and W. J. carried out the immunohistochemical analysis. X.T contributed to the data analysis. W.Y. reviewed and edited the manuscript. R.B. conceived of the study and participated in its design and coordination. All authors have read and approved the final manuscript.

\section{Funding}

This research was funded by National Natural Foundation Science of China, grant number NSFC 81802597".

\section{Availability of data and materials}

The datasets generated and /or analysed during the current study are not publicly available due the institutional review board restricts the use of the datasets to the current study only.

\section{Ethics approval and consent to participate}

This study was approved by the institutional review board Facility Ethical Committee (Fudan University Cancer Center Ethics Committee, China; approval No. 050432-4-121B, 13 December 2012).

\section{Consent for publication}

Not applicable.

\section{Competing interests}

The authors have no conflicts of interest to declare.

\section{Author details \\ 'Department of Pathology, Fudan University Shanghai Cancer Center, Fudan University, 270 Dong An Road, 200032 Shanghai, China. ${ }^{3}$ Department of Oncology, Shanghai Medical College, Fudan University, Shanghai, China. ${ }^{2}$ Departments of Pathology, Obstetrics and Gynecology Hospital of Fudan University, Shanghai, China.}

Received: 14 December 2020 Accepted: 25 January 2021 Published online: 04 February 2021

\section{References}

1. Boyd J. Molecular genetics of hereditary ovarian cancer. Oncology (Williston Park). 1998;12(3):399-406. discussion 409 - 10, 413.
2. Ligtenberg MJ, Kuiper RP, Geurts van Kessel A, et al. EPCAM deletion carriers constitute a unique subgroup of Lynch syndrome patients. Fam Cancer. 2013;12(2):169-74

3. Helder-Woolderink JM, Blok EA, Vasen HF, et al. Ovarian cancer in Lynch syndrome; a systematic review. Eur J Cancer. 2016;55:65-73.

4. Nakonechny QB, Gilks CB. Ovarian Cancer in Hereditary Cancer Susceptibility Syndromes. Surg Pathol Clin. 2016;9(2):189-99.

5. Lu KH, Dinh M, Kohlmann W, et al. Gynecologic cancer as a "sentinel cancer" for women with hereditary nonpolyposis colorectal cancer syndrome. Obstet Gynecol. 2005;105(3):569-74.

6. Baglietto L, Lindor NM, Dowty JG, et al. Risks of Lynch syndrome cancers for MSH6 mutation carriers. J Natl Cancer Inst. 2010;102(3):193-201.

7. Pal T, Permuth-Wey J, Sellers TA. A review of the clinical relevance of mismatch-repair deficiency in ovarian cancer. Cancer. 2008;113(4):733-42.

8. Watson P, Vasen HFA, Mecklin JP, et al. The risk of extra-colonic, extraendometrial cancer in the Lynch syndrome. Int J Cancer. 2008;123(2):444-9.

9. Chui MH, Ryan P, Radigan J, et al. The histomorphology of Lynch syndromeassociated ovarian carcinomas: toward a subtype-specific screening strategy. Am J Surg Pathol. 2014;38(9):1173-81.

10. Rambau PF, Duggan MA, Ghatage $P$, et al. Significant frequency of MSH2/ MSH6 abnormality in ovarian endometrioid carcinoma supports histotypespecific Lynch syndrome screening in ovarian carcinomas. Histopathology. 2016:69(2):288-97.

11. Matias-Guiu X, Stewart CJR. Endometriosis-associated ovarian neoplasia. Pathology. 2018;50(2):190-204.

12. Garg K, Leitao MM, Jr, Kauff ND, et al. Selection of endometrial carcinomas for DNA mismatch repair protein immunohistochemistry using patient age and tumor morphology enhances detection of mismatch repair abnormalities. Am J Surg Pathol. 2009;33(6):925-33.

13. Shia J, Black D, Hummer AJ, et al. Routinely assessed morphological features correlate with microsatellite instability status in endometrial cancer. Hum Pathol. 2008;39(1):116-25.

14. Bi R,Tu XY, Xiao YX, et al. Expression of DNA mismatch repair protein in endometrial carcinomas and its correlation with clinicopathologic features. Zhonghua Bing Li Xue Za Zhi. 2016;45(5):302-7.

15. Bennett JA, Morales-Oyarvide $V$, Campbell $S$, et al. Mismatch repair protein expression in clear cell carcinoma of the ovary: incidence and morphologic associations in 109 cases. Am J Surg Pathol. 2016:40(5):656-63.

16. Wiegand KC, Shah SP, Al-Agha OM, et al. ARID1A mutations in endometriosisassociated ovarian carcinomas. N Engl J Med. 2010;363(16):1532-43.

17. Jones $S$, Wang $T L$, Shih le $M$, et al. Frequent mutations of chromatin remodeling gene ARID1A in ovarian clear cell carcinoma. Science. 2010;330(6001):228-31.

18. Chandler RL, Damrauer JS, Raab JR, et al. Coexistent ARID1A-PIK3CA mutations promote ovarian clear-cell tumorigenesis through protumorigenic inflammatory cytokine signalling. Nat Commun. 2015;6:6118.

19. Ye S,Yang J, You Y, et al. Clinicopathologic significance of HNF-1 beta, AIRD1A, and PIK3CA expression in ovarian clear cell carcinoma: a tissue microarray study of 130 cases. Medicine. 2016;95(9):e3003.

20. Huang HN, Lin MC, Huang WC, et al. Loss of ARID1A expression and its relationship with PI3K-Akt pathway alterations and ZNF217 amplification in ovarian clear cell carcinoma. Mod Pathol. 2014;27(7):983-90.

21. Mutch DG, Prat J. 2014 FIGO staging for ovarian, fallopian tube and peritoneal cancer. Gynecol Oncol. 2014;133(3):401-4.

22. Hecht JL, Kotsopoulos J, Gates MA, et al. Validation of tissue microarray technology in ovarian cancer: results from the Nurses' Health Study. Cancer Epidemiol Biomarkers Prev. 2008;17(11):3043-50.

23. Katagiri A, Nakayama K, Rahman MT, et al. Loss of ARID1A expression is related to shorter progression-free survival and chemoresistance in ovarian clear cell carcinoma. Mod Pathol. 2012;25(2):282-8.

24. Sepulveda AR, Hamilton SR, Allegra CJ, et al. Molecular Biomarkers for the Evaluation of Colorectal Cancer: Guideline From the American Society for Clinical Pathology, College of American Pathologists, Association for Molecular Pathology, and American Society of Clinical Oncology. Arch Pathol Lab Med. 2017:141(5):625-57.

25. Longacre TA, Broaddus $R$, Chuang LT, et al. Template for reporting results of biomarker testing of specimens from patients with carcinoma of the endometrium. Arch Pathol Lab Med. 2017;141(11):1508-12.

26. Graham RP, Kerr SE, Butz ML, et al. Heterogenous MSH6 loss is a result of microsatellite instability within MSH6 and occurs in sporadic and hereditary colorectal and endometrial carcinomas. Am J Surg Pathol. 2015;39(10):1370-6. 
27. Therasse P, Arbuck SG, Eisenhauer EA, et al. New guidelines to evaluate the response to treatment in solid tumors. European Organization for Research and Treatment of Cancer, National Cancer Institute of the United States, National Cancer Institute of Canada. J Natl Cancer Inst. 2000;92(3):205-16.

28. Bennett JA,Arbuck SG, Eisenhauer EA, et al. Incidence of mismatch repair protein deficiency and associated clinicopathologic features in a cohort of 104 ovarian endometrioid carcinomas. Am J Surg Pathol. 2019;43(2):235-43.

29. Zannoni GF, Santoro A, Angelico G, et al. Clear cell carcinoma of the endometrium: an immunohistochemical and molecular analysis of 45 cases. Hum Pathol. 2019;92:10-7.

30. Parra-Herran C, Bassiouny D, Lerner-Ellis J, et al. p53, mismatch repair protein, and POLE abnormalities in ovarian clear cell carcinoma: an outcome-based clinicopathologic analysis. Am J Surg Pathol. 2019;43(12):1591-9.

31. Ferguson SE, Aronson M, Pollett A, et al. Performance characteristics of screening strategies for Lynch syndrome in unselected women with newly diagnosed endometrial cancer who have undergone universal germline mutation testing. Cancer. 2014;120(24):3932-9.

32. Jensen KC, Mariappan MR, Putcha GV, et al. Microsatellite instability and mismatch repair protein defects in ovarian epithelial neoplasms in patients 50 years of age and younger. Am J Surg Pathol. 2008;32(7):1029-37.

33. Helder-Woolderink JM, Blok EA, Vasen HF, et al. Ovarian cancer in Lynch syndrome; a systematic review. Eur J Cancer (Oxford, England: 1990). 2016;55:65-73.

34. Ryan NAJ, Evans DG, Green K, et al. Pathological features and clinical behavior of Lynch syndrome-associated ovarian cancer. Gynecol Oncol. 2017;144(3):491-5.

35. Ketabi Z, Bartuma K, Bernstein I, et al. Ovarian cancer linked to Lynch syndrome typically presents as early-onset, non-serous epithelial tumors. Gynecol Oncol. 2011;121(3):462-5.

36. Soliman PT, Broaddus RR, Schmeler KM, et al. Women with synchronous primary cancers of the endometrium and ovary: do they have Lynch syndrome? J Clin Oncol. 2005;23(36):9344-50.

37. Kobel M, Tessier-Cloutier B, Leo J, et al. Frequent mismatch repair protein deficiency in mixed endometrioid and clear cell carcinoma of the endometrium. Int J Gynecol Pathol. 2017;36(6):555-61.

38. Aysal A, Karnezis A, Medhi I, et al. Ovarian endometrioid adenocarcinoma: incidence and clinical significance of the morphologic and immunohistochemical markers of mismatch repair protein defects and tumor microsatellite instability. Am J Surg Pathol. 2012;36(2):163-72.

39. Lowery WJ, Schildkraut JM, Akushevich L, et al.Loss of ARID1A-associated protein expression is a frequent event in clear cell and endometrioid ovarian cancers. Int J Gynecol Cancer. 2012;22(1):9-14.

40. Xiao W, Awadallah A, Xin W. Loss of ARID1A/BAF250a expression in ovarian endometriosis and clear cell carcinoma. Int J Clin Exp Pathol. 2012;5(7):642-50.

41. Yamamoto S, Tsuda H, Takano M, et al. Loss of ARID1A protein expression occurs as an early event in ovarian clear-cell carcinoma development and frequently coexists with PIK3CA mutations. Mod Pathol. 2012;25(4):615-24.

42. Chou A, Toon CW, Clarkson A, et al. Loss of ARID1A expression in colorectal carcinoma is strongly associated with mismatch repair deficiency. Hum Pathol. 2014;45(8):1697-703.

43. Wang K, Kan J, Yuen ST, et al. Exome sequencing identifies frequent mutation of ARID1A in molecular subtypes of gastric cancer. Nat Genet. 2011:43(12):1219-23.

44. Bosse T, ter Haar NT, Seeber LM, et al. Loss of ARID1A expression and its relationship with PI3K-Akt pathway alterations, TP53 and microsatellite instability in endometrial cancer. Mod Pathol. 2013;26(11):1525-35.

45. Allo G, Bernardini MQ, Wu RC, et al. ARID1A loss correlates with mismatch repair deficiency and intact p53 expression in high-grade endometrial carcinomas. Mod Pathol. 2014;27(2):255-61.

46. Shen J, Peng $Y$, Wei L, et al. ARID1A deficiency impairs the DNA damage checkpoint and sensitizes cells to PARP inhibitors. Cancer Discov. 2015;5(7): 752-67.

47. Shen J, Ju Z, Zhao W, et al. ARID1A deficiency promotes mutability and potentiates therapeutic antitumor immunity unleashed by immune checkpoint blockade. Nat Med. 2018;24(5):556-62.

48. Stewart CJ, Bowtell DD, Doherty DA, et al. Long-term survival of patients with mismatch repair protein-deficient, high-stage ovarian clear cell carcinoma. Histopathology. 2017;70(2):309-13.

\section{Publisher's Note}

Springer Nature remains neutral with regard to jurisdictional claims in published maps and institutional affiliations.

\section{Ready to submit your research? Choose BMC and benefit from:}

- fast, convenient online submission

- thorough peer review by experienced researchers in your field

- rapid publication on acceptance

- support for research data, including large and complex data types

- gold Open Access which fosters wider collaboration and increased citations

- maximum visibility for your research: over $100 \mathrm{M}$ website views per year

At BMC, research is always in progress.

Learn more biomedcentral.com/submissions 